\title{
CIDADE PRÓXIMA, REGIÃO DISTANTE: OS OBSTÁCULOS A UMA CIDADE-REGIÃO NO ESTADO DO RIO DE JANEIRO
}

Diego Santos Vieira de Jesus*

\begin{abstract}
Resumo
O objetivo é examinar os obstáculos do arranjo populacional Rio de Janeiro/RJ para a articulação com outros arranjos no próprio Estado e as dificuldades na formação de aglomeração policêntrica e multifuncional na forma de cidade-região. Com base no referencial teórico de Allen Scott e em uma metodologia qualitativa focada em pesquisas documental e bibliográfica, o argumento central deste ensaio teórico que utiliza o Estado do Rio de Janeiro como estudo de caso aponta que tais obstáculos estão relacionados ao fato de que o Estado do Rio de Janeiro desenvolveu uma fraca rede urbana por conta da existência de poucos centros intermediários, em particular fora dos limites metropolitanos, em face das deficiências de infraestrutura produtiva. Esses centros não se definiram como alternativas para a localização industrial ou serviços especializados interconectados. Os resultados comprovam que, mais recentemente, as articulações críticas da produção, comércio e relações financeiras foram enfraquecidas com o agravamento da violência urbana, a crise econômica e fiscal do Estado e as denúncias de corrupção envolvendo autoridades estaduais, bem como a falta de estímulos à diversidade da produção cultural e a limitação de recursos para a inovação. Conclui-se que problemas previamente existentes dificultam a integração necessária à constituição de uma cidade-região, como o déficit políticosocial de cada arranjo ao administrar questões geradas ou alimentadas pela integração econômica no próprio arranjo.
\end{abstract}

Palavras-chave: Cidade-região. Rio de Janeiro. Capitalismo cognitivo. Planejamento urbano. Planejamento regional.

\footnotetext{
* Doutor em Relações Internacionais pela PUC-Rio e docente e pesquisador do Programa de Mestrado Profissional em Gestão da Economia Criativa da ESPM-Rio.dvieira@espm.br
} 
1 A identificação de um arranjo populacional tipicamente emprega a noção de integração, medida pelos movimentos pendulares para trabalho e estudo, ou a contiguidade urbana, sem levar necessariamente em conta questões referentes às funções dos centros urbanos (IBGE, 2016); porém, entende-se neste estudo que tais movimentos e a contiguidade podem ser importantes como bases para a aglomeração e a lógica interativa que tragam articulações críticas da produção, comércio e relações financeiras.

\section{Introdução}

Desde meados da década de 1950, é possível observar o crescimento e a disseminação das chamadas "cidades-região", incentivadas pelo desenvolvimento do capitalismo e da globalização. A expressão se refere a um conjunto de condições estruturais cujas bases estão nos processos de aglomeração e na lógica interativa do nexo territorial urbano, que fazem com que tais locais tenham um papel ativo como atores econômicos em âmbito mundial e tragam articulações críticas de produção, comércio e relações financeiras, que fazem a mediação entre suas economias nacionais imediatas e o sistema global. Tais cidades-região configuram-se como centros nacionais e internacionais de produção cultural, inovação e padrões de migração e focos de estratégias de reescalonamento estatal. Porém, seu gigantismo implica que elas enfrentem desafios na construção de arcabouços viáveis de governança, muitos dos quais estão relacionados à intensificação do uso estetizado da terra, à gentrificação, à polarização social, à informalidade e ao surgimento de paisagens pós-suburbanas (SCOTT, 2019).

Autores como Scott (2019) já identificam a formação de uma cidade-região no Estado do Rio de Janeiro. Outros como Magalhães (2008) observam apenas manifestações incipientes dessa constituição não apenas no Rio de Janeiro, mas em Minas Gerais e no Paraná. Entretanto, existem obstáculos à configuração de articulações entre os arranjos populacionais ${ }^{1}$ no próprio Estado do Rio de Janeiro que apontem para uma aglomeração no perfil de uma cidade-região. Tendo isso em vista, o objetivo do artigo é examinar os obstáculos do arranjo populacional Rio de Janeiro/RJ na articulação com outros arranjos no próprio Estado e as dificuldades na formação de uma aglomeração policêntrica, multiagrupada e multifuncional na forma de uma cidade-região.

$\mathrm{O}$ argumento central aponta que tais obstáculos estão relacionados ao fato de que o Estado do Rio de Janeiro desenvolveu uma fraca rede urbana por conta da existência de poucos centros intermediários, em particular fora dos limites metropolitanos, em face das deficiências de infraestrutura produtiva. Esses centros não se definiram como alternativas para a localização industrial ou serviços especializados interconectados. Ademais, pretende-se verificar se, mais recentemente, as articulações críticas de produção, comércio e relações financeiras foram enfraquecidas com o agravamento da violência urbana, a crise econômica e fiscal do Estado e as denúncias de corrupção envolvendo autoridades estaduais, bem como a falta de estímulos à diversidade da produção cultural e a limitação de recursos para a inovação. Além da baixa interconectividade global de demais arranjos no Estado além do Rio de Janeiro/RJ - diferentemente da 
alta conectividade existente em cidades-região em torno de Nova York ou Londres entre os países desenvolvidos e Shanghai entre os emergentes -, problemas previamente existentes dificultam a integração necessária a uma cidade-região, como o déficit político-social de cada arranjo ao administrar questões geradas ou alimentadas pela integração econômica.

Em termos das considerações metodológicas, o estudo qualitativo aqui realizado é de caráter exploratório. Ele assume o perfil mais próximo de ensaio teórico do que de uma pesquisa empírica baseada na coleta de dados primários. Ele faz uso da pesquisa bibliográfica e documental que permitem a inclusão de dados mais robustos que sustentem as afirmações, as colocações e as conclusões, por exemplo, dados populacionais e relacionados à renda, tendo como estudo de caso o estado do Rio de Janeiro. Os resultados apresentados inserem-se no contexto das pesquisas desenvolvidas por mim no Observatório da Marca Rio (OM), que tem como objetivo desenvolver um composto para a gestão da marca da cidade do Rio de Janeiro a partir da consideração de evidências físicas e simbólicas das identidades da marca, da imagem construída a partir da comunicação da marca, sobre ela e sua reputação. Durante as pesquisas, verificou-se que os obstáculos à formação de uma cidade-região no Estado do Rio de Janeiro poderiam estar associados à existência de poucos centros intermediários interconectados à capital e a problemas fiscais, políticos e socioculturais que dificultariam as articulações críticas da produção, do comércio e das relações financeiras da capital com o restante do Estado e incidiriam negativamente sobre a identidade, a imagem e a reputação da mesma. $\mathrm{O}$ artigo se debruça sobre esses obstáculos a fim de que, em estudos futuros, seja possível beber nas fontes de seus resultados a fim de se analisarem os efeitos de tais obstáculos sobre a gestão da marca da cidade.

\section{As cidades-região}

A ideia de cidade-região foi apresentada no debate acadêmico na década de 1910 por Geddes (1915), que se debruçou sobre o estudo das cidades no final do século XIX e no começo do século XX. Para o autor, a cidade-região teria um centro urbano claro, que se desenvolveria radialmente na direção do interior (BEZERRA, 2017). Porém, o conceito de cidaderegião passou a ganhar mais atenção a partir da década de 1980, com o surgimento de grandes "cidades mundiais" (FRIEDMANN; WOLFF, 1982; KNOW; TAYLOR, 1995) e "cidades globais" (SASSEN, 1991). A tendência refletia a emergência de grandes áreas urbanizadas espacialmente estendidas ao redor do mundo, sendo cada uma delas ancorada em um ou mais centros metropolitanos e se espalhando para áreas internas mais difusas. Em tais áreas internas, existiam terras agrícolas, alojamentos, 
propriedades industriais e comerciais e centros de serviços locais. Também chamadas de "regiões megaurbanas" (LAQUIAN, 2005) ou "metrópoles policêntricas” (HALL; PAIN, 2012), as cidades-região estão em evidência em áreas diversas, ainda que apresentem diferentes níveis de integração ao sistema capitalista e manifestações empíricas distintas (SCOTT, 2019).

Já Parr (2005) entende que uma cidade-região refere-se a um polo metropolitano somado a toda a sua área de influência, o que poderia englobar, por exemplo, o território de um país inteiro. Segundo Bezerra (2017), esse autor afirmava que a importância da cidade-região estava na organização espacial da dimensão territorial do país, particularmente em termos das interações espaciais vinculadas às atividades comerciais, à mobilidade espacial da população e ao movimento de capitais. Outros autores compreendem que tal conceito baseia-se em processos de reestruturação produtiva e reconfiguração territorial em torno da área metropolitana em escala regional (LENCIONI, 2000; RANDOLPH, 2005), ideia em torno da qual este artigo mostra-se embasado. Segundo essa perspectiva, o núcleo da cidade-região funciona como um meio de acesso às atividades econômicas do território, pelo qual passam fluxos de capitais, mercadorias, pessoas e informações, incentivados pelo adensamento das redes e associados por modernos sistemas de transportes e comunicação (LENCIONI, 2000).

Ainda que houvesse um surgimento ainda incipiente de cidadesregião em Estados capitalistas avançados na década de 1960, as crises da década de 1970 - como as do petróleo - foram acompanhadas por uma interrupção severa do crescimento urbano conforme as forças de aglomeração da economia clássica fordista diminuíram. Com o advento do pós-fordismo nas décadas de 1980 e 1990, alimentado pela globalização, uma série de desenvolvimentos interdependentes como os avanços nas tecnologias de informação e comunicação e a difusão de novos sistemas de produção mobilizou as habilidades mentais, comportamentais e afetivas dos trabalhadores e levou a mudanças nas estratégias de governança e de formulação da decisão que alimentaram a difusão de mercados competitivos. Mudanças ocorriam não apenas em áreas do planeta que tinham passado por uma fase fordista, mas também nas que não tinham passado ou onde elas ainda estavam em curso (SCOTT, 2019). Soja (2000) aponta a crise de uma "metrópole fordista-keynesiana" a partir da década de 1960 em países centrais como marco de uma reestruturação da atuação do Estado enquanto provedor de meios de consumo coletivo na esfera da reprodução e da presença estável e empregadora da indústria fordista no meio metropolitano na esfera da produção. Tal restruturação passaria a ser marcada, do ponto de vista econômico, pela emergência de formas flexíveis de organização das cadeias produtivas em um contexto pós-fordista e 
na atuação de um Estado neoliberal. No contexto dessa restruturação, surgiriam as cidades-região como sistemas regionais e policêntricos mais amplos de assentamentos nodais que interagem entre eles (SOJA, 2000).

Com o desenvolvimento de uma economia que explorava elementos culturais e cognitivos, ofereciam-se melhores condições de possibilidade para que se desenvolvessem ainda mais cidades-região, apesar do fato de que se geravam também novos problemas na vida urbana. A "nova economia" deu novo ânimo às economias de aglomeração, sem as quais as vantagens competitivas das cidades como concentradoras de capital e trabalho seriam insustentáveis, e estimulou o desenvolvimento econômico local ao possibilitar que centros urbanos favorecidos buscassem nichos especializados dentro de uma divisão global de trabalho e exportassem seus produtos para mercados diferenciados. Embora as modalidades pré-fordistas e fordistas de organização econômica estejam longe de ser completamente substituídas pelo capitalismo fundamentado no conhecimento, uma série de setores novos ou restruturados, com base em tecnologias eletrônicas ou em processos de trabalho cognitivo e cultural, penetrou em inúmeras áreas da economia moderna e se concentrou em locações urbanas favorecidas, como os setores de produção intensiva em tecnologia e desenvolvimento de softwares, serviços financeiros e corporativos e setores culturais de múltiplos tipos (SCOTT, 2019). O crescimento dos entornos dos centros muitas vezes está relacionado ao custo de localização mais alto na metrópole, à menor atuação de sindicatos nas áreas menos adensadas e à agilização do acesso a serviços especializados pela proximidade relativa da metrópole. A atração do investimento pós-fordista em um ambiente regional amplo é definida pela conexão ao mercado externo - como portos e aeroportos - e pela existência de ambientes de formação de mão de obra especializada em tecnologias avançadas e pesquisa científica (MAGALHÃES, 2008).

Todavia, a acumulação flexível anteriormente mencionada englobou desigualdades no padrão de desenvolvimento tanto entre setores da economia - como se vê no setor de serviços - como entre regiões geográficas, conforme se verifica na criação de conjuntos industriais completamente novos em áreas até então subdesenvolvidas. Tais transformações mostramse territorializadas em espaços específicos, que são frequentemente denominados "regiões"2. Essas regiões definidas a partir de processos econômicos raramente coincidem com as regiões político-institucionais, de forma a haver um déficit político na capacidade das cidades-região de administrarem questões geradas ou alimentadas pela integração econômica, como a degradação ambiental, a falta de saneamento básico, o desemprego e a carência de infraestrutura urbana. Há uma nítida dificuldade de se definirem arranjos políticos entre os atores regionais, o que pode tornar
2 É preciso reconhecer que o termo "região" pode ter uma multiplicidade de definições em áreas como a Geografia, a Economia e os Estudos sobre Planejamento Urbano. Alguns autores, inclusive, procuram evitar o termo por conta da grande possibilidade de dispersão conceitual. Contudo, neste artigo, o conceito é retomado justamente para que se possa debater, a partir dessa multiplicidade de critérios, as oportunidades e os desafios que surgem no conceito de cidaderegião. 
muito abstrata a avaliação da capacidade de resposta dessas cidades-região aos desafios regionais e globais (ARRAIS, 2008).

As localidades no espaço intraurbano nos quais níveis relativamente altos de acessibilidade prevalecem são frequentemente sujeitas ao aumento no valor dos aluguéis e na densidade do uso da terra. Tal dinâmica pode desembocar na formação de centros comerciais hierárquicos, policêntricos e espacialmente ordenados em cidades-região. $\mathrm{O}$ centro comercial maior, mais diverso e mais visível em uma cidade-região tipicamente está localizado no centro gravitacional do sistema como um todo e serve como o centro das atividades de negócios dominantes de toda a área construída. A tendência de expansão pode também ser vista em cidadesregião em países menos desenvolvidos, nos quais setores avançados de varejo e serviços financeiros e relacionados a negócios também assumem papel importante. Produtores tendem a se localizar nos principais centros nos quais suas interações ricas em informação geram economias de aglomeração mutuamente sustentáveis. Essa região serve, ainda, como um centro de empregos para trabalhadores qualificados que venham de todas as partes da cidade. Entretanto, em face de sua centralidade e acessibilidade, grandes centros empresariais são suscetíveis à contínua intensificação do uso vigoroso da terra, que se vê na demolição de edificações em áreas centrais da cidade e sua substituição por prédios ainda mais altos com a ampliação do espaço físico. $\mathrm{O}$ status icônico dessas edificações é mais frequentemente transformado em símbolo estético. $\mathrm{O}$ redesenvolvimento dessas regiões é tipicamente acompanhado por grandes investimentos públicos e privados (SORKIN, 1992; SCOTT, 2019).

Concomitantemente à gentrificação que encorajou a saída de trabalhadores que não poderiam sustentar um nível de vida digno se continuassem a residir em tais locais, as cidades-região vêm observando, também, na perspectiva de Scott (2019), a polarização sociale a informalidade crescentes. As divisões primárias se materializam nas discrepâncias entre pessoas com comando sobre os bens materiais ou em melhor posição na divisão do trabalho. Divisões desse tipo são frequentemente articuladas com variações de raça, etnicidade, cultura, gênero e orientação sexual, por exemplo. Além disso, a diferenciação social é associada a populações migrantes subalternas que vêm de fora do centro da sociedade urbana, as quais são frequentemente alocadas em vizinhanças diferenciadas ou em nichos residenciais e assumem funções de baixa remuneração na economia informal local (WALDINGER, 2001). A fragmentação e a exclusão socioespacial assumem tamanha dimensão, de forma que classes mais abastadas passam a definir espacialidades próprias (MAGALHÃES, 2008). Nesse sentido, o espaço de uma cidade-região torna-se descontínuo. Em face de tais dinâmicas, tornam-se necessárias instituições de governança 
no nível das cidades-região, mas a geografia política das cidades-região é tipicamente composta por múltiplos governos municipais que têm fortes incentivos para focar em seus interesses específicos em âmbito local às custas da comunidade regional mais ampla (SCOTT, 2019).

\section{Os obstáculos a cidades-região no Brasil}

Grande parte da literatura que trata de cidades-região confundese com as experiências de geógrafos da escola californiana, como Scott (2019), Storper (1997) e Soja (2000), que demonstraram particular atenção ao estudo dos impactos políticos, econômicos e culturais da globalização na região do sul da Califórnia, região densamente povoada e tecnologicamente desenvolvida nos EUA (BEZERRA, 2017). No caso brasileiro, em termos de políticas governamentais, os arranjos metropolitanos - particularmente as regiões metropolitanas - receberam maior atenção que cidades médias e pequenas, por exemplo, não em razão da abrangência territorial mas pela concentração demográfica, tendo em vista que essas regiões abrigam a maior parte da população do país e têm fundamental papel na composição do PIB. Os desafios políticos na gestão de cidades médias e pequenas - em particular daquelas que integram regiões metropolitanas ou conurbações urbanas ou que compõem uma cidade-região - não se limitam estritamente a administrar o desafio demográfico privilegiando políticas de habitação e mobilidade, mas abarcam também lidar com temas como violência urbana, precária oferta de serviços de educação e saúde, problemas de saneamento básico, desemprego e concentração de renda (ARRAIS, 2008).

O conceito de "cidade-região" traz a lembrança de que se deve fomentar a discussão política em espaços interligados por uma densa rede urbana e caracterizados por desafios institucionais comuns; porém, é preciso considerar que a natureza e a operacionalidade do conceito no Brasil são diferentes das apresentadas nos EUA, na Europa ou na Ásia e que cada estrutura territorial e administrativa possui uma especificidade em termos de sistemas político-administrativos mais ou menos centralizados, o que influencia as possibilidades de coesão regional (ARRAIS, 2008). No caso brasileiro, dentre os elementos que dificultam a constituição de cidades-região, cabe citar a fragmentação generalizada no tecido socioespacial metropolitano nos grandes centros brasileiros, que ocorreu concomitantemente à formação de enclaves múltiplos, por exemplo, vê-se na territorialização das favelas pelo tráfico de drogas - que depende do caráter de enclave armado e territorializado para as bases de operações - e, por outro lado, a "autossegregação residencial" das elites urbanas em espaços isolados, vistos como dotados de mais segurança e representantes de status 
e distinção das classes mais altas, de forma a tornar a segregação social um valor (CALDEIRA, 1997; MAGALHÃES, 2008).

De acordo com o IBGE (2015), cerca de 55,9\% da população brasileira residia, em 2010, em arranjos populacionais, ou seja, agrupamentos de dois ou mais municípios com forte integração populacional devido aos movimentos pendulares para estudo ou trabalho ou à contiguidade entre as manchas urbanas. A maior quantidade desses arranjos se encontra na Região Sudeste (112), que englobam $72 \%$ da população da região $(57,8$ milhões). As três maiores concentrações urbanas ficaram localizadas na região: São Paulo/SP (19,6 milhões de habitantes), Rio de Janeiro/RJ (11,9 milhões) e Belo Horizonte/MG (4,7 milhões). Nas duas primeiras, o deslocamento para trabalho e estudo entre os municípios que as compõem é forte: São Paulo/SP conta com quase 1,8 milhões de pessoas, e o Rio de Janeiro/RJ, com cerca de 1 milhão. Nesta última, os maiores fluxos ocorrem entre os municípios de Niterói (RJ) e São Gonçalo (RJ), Duque de Caxias (RJ) e Rio de Janeiro (RJ), Nova Iguaçu (RJ) e Rio de Janeiro (RJ).

Segundo o IBGE, somente o arranjo São Paulo/SP articula-se mais intensamente a arranjos como Campinas/SP, Jundiaí/SP, Sorocaba/ SP, Baixada Santista/SP e São José dos Campos/SP, entre outros. Juntos, configuram uma aglomeração policêntrica ou multiagrupada que cumpre várias funções e potencializa a capacidade de produzir bens, prestar serviços, estabelecer parcerias e gerir recursos, de forma a se configurar como uma cidade-região. Tal cidade-região engloba 89 municípios e 11 arranjos populacionais, contando com 27,4 milhões de habitantes (IBGE, 2015). Tratando do caso de São Paulo, Lencioni (2000) coloca que a globalização e as adequações econômicas das forças produtivas impulsionaram as mudanças nas redes geográficas, proporcionando multiplicidade e disseminação de atividades pelo território. Com foco no ABC Paulista, Klink (2001) abordou que a cidade-região ali desenvolvida assumia novas atribuições em termos de desenvolvimento econômico devido à restruturação produtiva desde o fim do século passado. Cabe questionar a natureza dos obstáculos para que o arranjo populacional Rio de Janeiro/RJ não tenha desenvolvido o mesmo tipo de articulação com outros arranjos no próprio Estado.

\section{Os obstáculos a uma cidade-região no Estado do Rio de Janeiro}

Enquanto o arranjo populacional de São Paulo/SP - que não deve se confundir com a cidade-região que tal arranjo forma com Campinas/ SP, Jundiaí/SP, Sorocaba/SP, Baixada Santista/SP e São José dos Campos/ $\mathrm{SP}$ - concentrava 36 municípios e era marcado pela continuidade em 31 municípios desse total, o Rio de Janeiro/RJ soma 18 municípios em uma mancha urbanizada no total de 21 municípios nesse arranjo (IBGE, 2015). 
Os arranjos populacionais e as concentrações urbanas do Estado do Rio de Janeiro são exibidos na Figura 1.

Figura 1 - Arranjos populacionais e concentrações urbanas no Estado do Rio de Janeiro

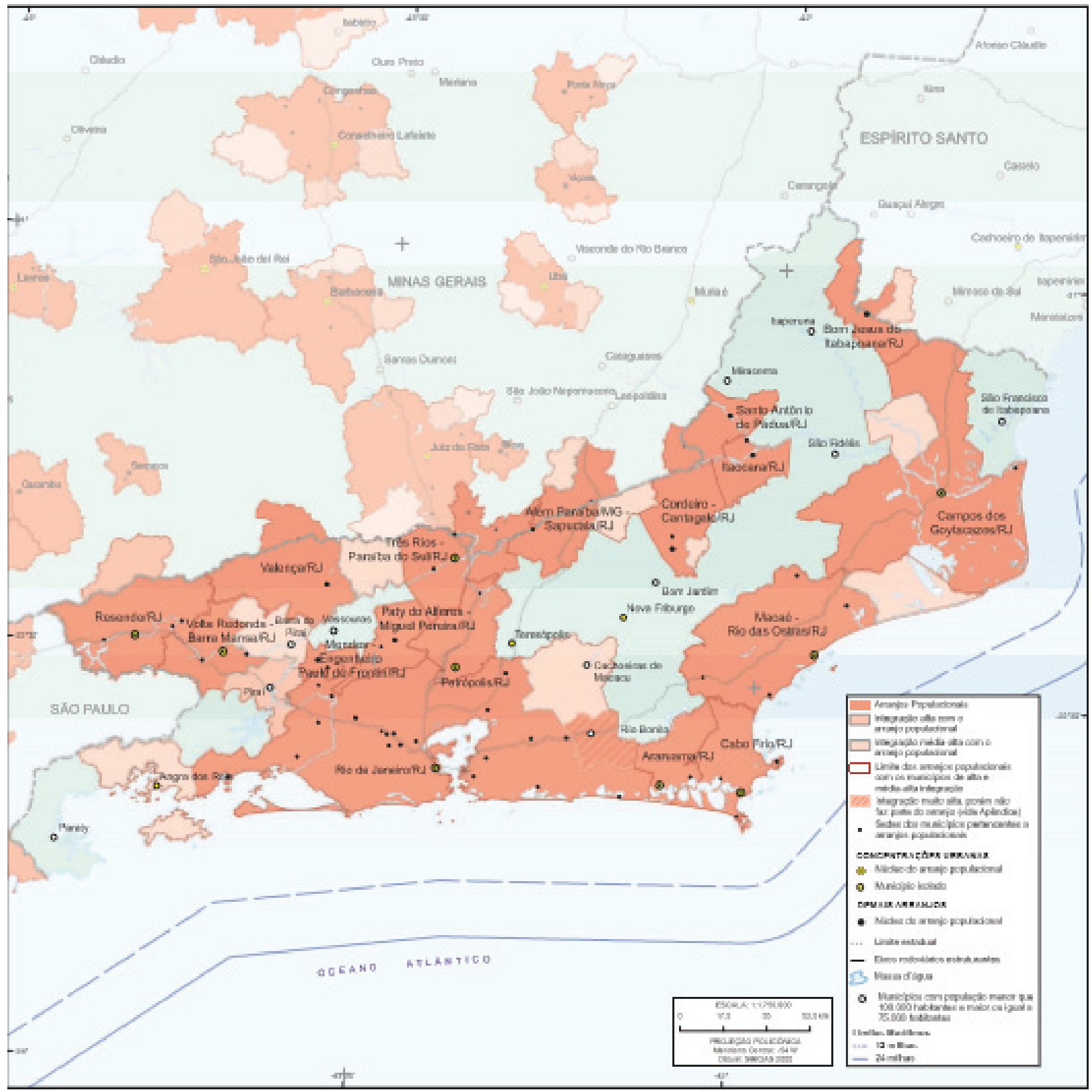

Fonte: IBGE (2016).

É possível apontar uma série de fatores que justificam a fraqueza ou a ausência de articulações críticas de produção, comércio e relações financeiras, necessárias a uma aglomeração policêntrica que potencialize a capacidade de produzir bens, prestar serviços, estabelecer parcerias e gerir recursos 
no Estado do Rio de Janeiro. Cabe indicar que a falta de uma economia regional e integrada mostra-se associada a uma fraca rede urbana no estado por conta da existência de poucos centros intermediários, em particular fora dos limites metropolitanos (LOUREIRO, 2006). O desequilíbrio na estrutura urbana do estado deve-se à ausência de reservas minerais, à debilidade da agropecuária e a pouca diversificação das atividades produtivas nos núcleos urbanos interioranos mais representativos e mesmo nos centros intermediários metropolitanos, os quais, apesar de terem uma economia relativamente mais diversificada, mantêm-se altamente dependentes das atividades econômicas e da infraestrutura de serviços do seu núcleo, a cidade do Rio de Janeiro (RUIZ, 2004). A concentração de produção e renda na capital está ligada a marcos da formação histórica fluminense no território, como o processo de acumulação mercantil, a estagnação da cafeicultura no interior, a grande utilização de mão de obra escrava e a separação político-administrativa com o exercício da função de capital nacional por quase duzentos anos, em que as funções urbanas nacionais sobrepuseram-se às locais. O entorno da capital apresentou poucos fatores aglomerativos que incentivassem maior integração produtiva, mesmo diante da aparente saturação industrial da região metropolitana do Rio de Janeiro (LOUREIRO, 2006).

No âmbito da própria região metropolitana do Rio de Janeiro, a baixa conectividade viária e a fraca articulação com as demais áreas do estado fortaleceram a polarização da capital (DAVIDOVICH, 2001). A preponderância da cidade do Rio de Janeiro freou o desenvolvimento de interligações secundárias entre as cidades do sistema urbano fluminense, de forma que a ampliação da rede de transportes visava não a atender ao desenvolvimento interno mas a sustentar o poderio econômico da capital (DUARTE, 1981). Uma série de municípios na periferia da cidade do Rio de Janeiro - como Nova Iguaçu, Duque de Caxias e São Gonçalo teve explosões demográficas desde a década de 1940, aliviando a pressão demográfica na capital e em Niterói, mas apresentou fracos núcleos produtivos ou com serviços de baixa complexidade, limitados pela renda reduzida de suas populações. Com deficiências de infraestrutura produtiva e urbana, não se definiram como alternativas para a localização industrial ou serviços especializados e se mantiveram subordinados à dinâmica da capital (LOUREIRO, 2006).

Para além dos limites da região metropolitana, poucos municípios assumiram porte intermediário, como Campos dos Goytacazes, desenvolvido pela cultura canavieira desde o início do século XVIII, mas cuja produtividade foi perdendo expressão nacional até meados do século XX. As ligações viárias do norte do estado com a capital desestimularam a diversificação das atividades em Campos, que depois experimentou uma 
retomada de seu crescimento com a exploração de petróleo na Bacia de Campos, bem como Macaé. Na Região Serrana, Petrópolis, Teresópolis e Nova Friburgo - que vem se destacando como polo de moda íntima-contam com alguma atividade industrial, mas se constituíram como extensões de lazer e turismo e áreas de segunda residência da elite carioca. No Médio Paraíba, Volta Redonda e Barra Mansa desenvolveram-se por intermédio de Companhia Siderúrgica Nacional, mas é nítida a pouca diversificação da atividade econômica, de modo a não se formar um complexo industrial integrado nem se gerar densidade urbana para serviços de média e alta complexidade. A atração de indústrias automotivas para Resende e Porto Real trouxe uma nova possibilidade de crescimento para tais áreas. Já municípios litorâneos como Cabo Frio, na Região dos Lagos, e Angra dos Reis, no Sul Fluminense, exploram mais intensamente o turismo, ainda que esta última abrigue estaleiros e usinas nucleares (NATAL, 2005).

A estrutura concentrada em setores tradicionais menos dinâmicos não contribuiu para a atração de investimentos nacionais e estrangeiros, de forma que a economia da capital operou como depositária de setores obsoletos com as revoluções industriais, de forma que a região teve uma participação inexpressiva nas indústrias de bens duráveis (DAIN, 1980). Em face do enfraquecimento da base industrial, a cidade do Rio de Janeiro passou a confiar mais na oferta de serviços, em especial os de apoio à produção e os mais promissores sendo integrados à indústria, como os serviços jurídicos e financeiros, contabilidade, auditoria, engenharia e publicidade. Porém, a queda dos serviços de suporte à produção relacionouse à diminuição relativa do parque industrial da cidade, e a saída de sedes de grandes empresas e bancos - em particular para São Paulo - com a redução do poder dirigente nacional impactou pesadamente o peso corporativo do município. Com a perda da posição de capital nacional, a cidade observou a transferência da sede do comando do sistema oficial monetário para Brasília (CYSNE, 1996), além de perder iniciativas na pesquisa científica aplicada, ter o desmonte de setores de alta tecnologia e se converter em exportadora de mão de obra qualificada para outras cidades, como São Paulo (LESSA, 2000; SCHWARTZMAN, 1993).

Mais recentemente, as articulações críticas de produção, comércio e relações financeiras, necessárias à constituição de uma cidade-região, foram enfraquecidas com o agravamento da violência urbana, a crise econômica e fiscal do Estado e as denúncias de corrupção envolvendo autoridades estaduais. No âmbito da segurança pública, o Estado foi alvo de uma intervenção federal ao longo de grande parte do ano de 2018, que visou a conter o comprometimento da ordem pública em face do agravamento da violência a partir da segunda metade de 2017. A situação remetia ao acirramento das crises política e econômico-financeira no Rio de Janeiro, 
3 A Operação Lava Jato é um conjunto de investigações iniciadas em março de 2014 pela Polícia Federal. O objetivo inicial era apurar esquemas de lavagem de dinheiro nos quais estavam envolvidos políticos, funcionários da Petrobras e grandes empresários. Desde seu início, a operação investigou crimes de corrupção, gestão fraudulenta e obstrução de justiça, dentre outros, e cumpriu mandados de busca e apreensão, prisão temporária e prisão preventiva. e a intervenção buscaria um sistema mais robusto de segurança social para uma coordenação mais estreita entre as forças de segurança e a ampliação da capacidade operacional e da maior integração da inteligência (ROSSI, 2018). Entretanto, seus resultados não foram tão expressivos como se imaginava originalmente: a letalidade violenta no Estado caiu somente 1\% entre os primeiros trimestres de 2017 e 2018: 1846 pessoas mortas em 2017 e 1806 em 2018. Os homicídios decorrentes de oposição à intervenção policial apresentaram queda de 11,4\% em março de 2018 no Estado. Em 2018, foram registradas 109 mortes, 14 a menos do que o mesmo período do ano anterior. Entretanto, na cidade do Rio de Janeiro, houve aumentos expressivos de tal letalidade no período nas regiões da Rocinha, Ipanema, Leblon, Gávea, Jardim Botânico, Lagoa, São Conrado e Vidigal (G1 RIO, 2018), em grande parte explicada pela guerra entre policiais e traficantes e entre grupos criminosos rivais nas favelas da Zona Sul da cidade.

A recessão econômica do Estado do Rio de Janeiro - concomitante à retração nas atividades da indústria do petróleo e à queda da arrecadação - também conduziu à pauperização crescente da população. Como coloca Wermuth (2011), a população economicamente hipossuficiente, quando abandonada pelo Estado nas dimensões social e econômica, pode buscar, por meio da delinquência, a satisfação das necessidades básicas e dos desejos de consumo. O quadro de crise foi agravado com a corrupção disseminada pelo aparato político, evidente com a prisão dos ex-governadores Sérgio Cabral Filho em 2016 no contexto da "Operação Lava Jato"3" e Luiz Fernando Pezão em 2018, acusado de receber quase $\mathrm{R} \$ 40$ milhões em propinas de contratos do governo estadual. Além deles, foram presos ex-secretários e conselheiros do Tribunal de Contas. A situação conduziu não apenas a problemas como a escassez de verbas para o pagamento de salários dos servidores estaduais, mas ao gradual colapso de programas do governo do Estado, como as Unidades de Pronto-Atendimento (UPAs) e as Unidades de Polícia Pacificadora (UPPs) ao longo de 2017 (O ESTADO DE S. PAULO, 2017).

Scott (2019) ressalta que as cidades-região configuram-se como centros nacionais e internacionais de produção cultural, inovação e padrões de migração e focos de estratégias de reescalonamento estatal. Entretanto, grande parte dos principais setores criativos formais - caracterizados pelo desenvolvimento de atividades produtivas que têm como processo principal um ato criativo gerador de um produto e a dimensão simbólica é determinante do seu valor (OLIVEIRA, 2016) - concentra-se primordialmente na região metropolitana do Rio de Janeiro, particularmente nas Zonas Sul e Central da capital e no bairro da Barra da Tijuca. Quase 80\% dos postos relacionados ao trabalho na economia criativa no estado se concentram na cidade do Rio de Janeiro, os quais correspondiam a pouco mais que 
$10 \%$ dos empregos gerados no fim da década de 2000. Outros arranjos populacionais no Estado destacavam-se por setores criativos como Cabo Frio/RJ e Petrópolis/RJ, nos quais o turismo tem amplo destaque, mas se mostram pulverizados em relação à capital e reduzidos em termos de produção cultural e artística comparados ao Rio de Janeiro/RJ. No que diz respeito à diversidade das manifestações culturais, basta verificar o exemplo da própria capital a fim de se identificar como tal diversidade é tolhida. As deficiências na gestão e o escasso conhecimento técnico nos órgãos fiscalizadores conduzem à decadência física e simbólica do Patrimônio Cultural na cidade, o que ocorre concomitantemente às pressões exercidas por grupos particulares e à expansão urbana desordenada, muitas vezes para o uso comercial do espaço (JESUS, 2017b).

A violência disseminada na esfera pública dificulta o acesso a uma série de equipamentos de lazer e cultura no estado do Rio de Janeiro, como as lonas e arenas culturais nas Zonas Norte e Oeste da capital. Grandes eventos culturais como o Rock In Rio em 2017 foram marcados pela dinâmica de guerras entre traficantes e a intervenção das Forças Armadas na favela da Rocinha durante o evento, cujos impactos refletiram-se na percepção de cariocas e turistas sobre a realização do festival (PREFEITURA DO RIO DE JANEIRO, 2017). A crise reduziu a quantidade de verbas a serem utilizadas na manutenção de equipamentos culturais que promovem as singularidades das regiões cariocas e no pagamento de funcionários desses equipamentos. No âmbito de eventos culturais, o ajuste fiscal promovido pelo prefeito Marcelo Crivella em 2017 atingiu as finanças de alguns dos principais eventos culturais da cidade, como os desfiles das escolas de samba de 2018 e a Parada do Orgulho LGBTI-Rio. Crivella foi acusado de deixar que suas convicções religiosas interferissem nas decisões administrativas (MARTÍN, 2017).

Em relação especificamente à inovação, a crise orçamentária e as denúncias de corrupção envolvendo agentes de inovação no setor político dificultaram a execução do papel dos governos como incentivadores e financiadores de empresas baseadas em novas tecnologias e pesquisas científicas, o que prejudica a cooperação governamental com o setor privado e as universidades (MOREIRA, 2018). As indústrias e as empresas em geral investiram mais em inovação durante a crise, mas algumas das mais importantes estavam altamente endividadas ou envolvidas em sistemas de corrupção com entes governamentais, o que limitava os recursos para inovação (BATISTA; ALMEIDA, 2018). Além da intensificação dessas limitações, as universidades no Estado do Rio de Janeiro sofreram pesadamente com as limitações de verbas para a ciência e tecnologia, o que inviabilizou pesquisas, desmantelou grupos de pesquisa e conduziu a uma “fuga de cérebros" para fora do Rio de Janeiro e do Brasil (LEWER, 2017). 
Uma cidade-região deve, de acordo com Scott (2019), ter um papel ativo como ator político-econômico em âmbito mundial. Porém, no Estado do Rio de Janeiro, somente a cidade do Rio de Janeiro parece ter uma atuação internacional mais expressiva por meio de sua paradiplomacia, que se caracteriza como o desenvolvimento, por parte de governos subnacionais, de uma agenda externa de atuação além das fronteiras territoriais do Estado, com foco nos interesses locais, e abarca atividades como missões internacionais, participação em feiras e eventos internacionais, esquemas de cooperação técnica, trocas de experiências e acordos entre cidades (JESUS, 2017a). Entretanto, os demais arranjos populacionais no Estado do Rio de Janeiro apresentam baixa interconectividade global.

Autores como Scott (2019) e Soja (2000) apontam na formação de uma cidade-região uma série de problemas que se desenvolvem ou se potencializam. No caso do Estado do Rio de Janeiro, uma série de obstáculos já se coloca antes mesmo da constituição da cidade-região, não se constituindo as condições de possibilidade para seu desenvolvimento. Dentre elas, cabe citar a estratificação do espaço urbano e o foco excessivo dos governos municipais em seus interesses específicos em âmbito local às custas da comunidade regional mais ampla, em grande parte explicada pelas disputas interpartidárias entre diferentes níveis de governo e com lideranças de outras cidades e pela manutenção de esquemas de corrupção. Como aponta Abreu (1987), embora o crescimento urbano desordenado tenha criado escala de demanda para a diversificação e ampliação da oferta de bens e serviços, o estado teve suas infraestruturas urbanas, físicas - como moradias, saneamento e transporte público - e social - educação, saúde e lazer - pressionadas ao limite. Isso agravou problemas como degradação ambiental, questões de mobilidade urbana, déficit habitacional e violência urbana. Ademais, os déficits sociais são supridos de maneira precária, de forma a conduzir ao crescimento das favelas, loteamentos irregulares e população de rua e ao avanço do tráfico de drogas, que teve especialmente nos morros da capital uma localização estratégica de defesa e logística (LOUREIRO, 2006; PRETECEILLE; VALLADARES, 2000). Nesse contexto, a polarização e a informalidade que tendem a crescer com a formação de uma cidade-região já podem ser observadas antes mesmo de ela estar plenamente constituída.

A estratificação ainda mais profunda entre trabalhadores qualificados em setores técnicos, administrativos e criativos com renda mais alta e uma massa de trabalhadores não qualificados e de renda mais baixa, que vivem em condições precárias e ficam ainda nítidas na formação de uma cidaderegião, já se observa no estado. Há uma forte presença da elite na Zona Sul e em parte da Zona Oeste da cidade do Rio de Janeiro e na orla de Niterói. Nota-se que, ao se levar em consideração o rendimento nominal 
médio domiciliar na cidade do Rio de Janeiro, os cinco bairros com maior rendimento ficam localizados nas Zonas Sul e Oeste, e os cinco com menor rendimento, predominantemente na Zona Norte, como comprovam os Quadros 1 e 2.

Quadro 1 - Bairros com maior rendimento nominal médio domiciliar no Rio de Janeiro

\begin{tabular}{|c|c|c|}
\hline Bairro & Zona & Rendimento nominal médio domiciliar (em reais) \\
\hline Joá & Oeste & 17.537 \\
\hline Lagoa & Sul & 14.707 \\
\hline São Conrado & Sul & 13.473 \\
\hline Barra da Tijuca & Oeste & 12.113 \\
\hline Leblon & Sul & 11.633 \\
\hline
\end{tabular}

Fonte: IBGE (2010).

Quadro 2 - Bairros com menor rendimento nominal médio domiciliar no Rio de Janeiro

\begin{tabular}{|c|c|c|}
\hline Bairro & Zona & Rendimento nominal médio domiciliar (em reais) \\
\hline Costa Barros & Norte & 1.250 \\
\hline Barros Filho & Norte & 1.247 \\
\hline Manguinhos & Norte & 1.246 \\
\hline Acari & Norte & 1.141 \\
\hline Grumari & Oeste & 973 \\
\hline
\end{tabular}

Fonte: IBGE (2010).

Já a classe média aparece com maior peso e o subproletariado com menor renda principalmente as áreas suburbanas do Rio de Janeiro e Niterói, ao passo em que se tem a presença significativa tanto do proletariado terciário e do proletariado secundário quanto da classe média na periferia da capital e da região metropolitana. Há um claro predomínio do proletariado secundário, seguido pelo proletário terciário e pelo subproletariado nas áreas da periferia metropolitana e das favelas localizadas nos subúrbios da cidade do Rio de Janeiro, enquanto se tem um elevado peso dos agricultores - bem como operários da construção civil e trabalhadores domésticos - nas áreas situadas nas fronteiras de expansão da região metropolitana (LAGO, 2000). Os Quadros 3 e 4 evidenciam os cinco municípios com maior presença de população urbana e rural, respectivamente, e traduzem essa disparidade. 
Quadro 3 - Municípios com maior população urbana no Estado do Rio de Janeiro

\begin{tabular}{|c|c|c|}
\hline Município & População urbana & População rural \\
\hline Rio de Janeiro & 6323037 & 0 \\
\hline Niterói & 487327 & 0 \\
\hline Belford Roxo & 469261 & 0 \\
\hline São João de Meriti & 459356 & 0 \\
\hline Mesquita & 168403 & 0 \\
\hline
\end{tabular}

Fonte: IBGE (2010).

Quadro 4 - Municípios com maior população rural no Estado do Rio de Janeiro

\begin{tabular}{|c|c|c|}
\hline Município & População urbana & População rural \\
\hline Cabo Frio & 140466 & 45756 \\
\hline Campos dos Goytacazes & 418565 & 44980 \\
\hline Nova Friburgo & 159335 & 22681 \\
\hline São Francisco de Itabapoana & 21090 & 20267 \\
\hline Teresópolis & 145473 & $\mathbf{1 8 3 3 2}$ \\
\hline
\end{tabular}

Fonte: IBGE (2010).

Em uma cidade-região, grandes investimentos públicos e privados são tipicamente feitos em instalações culturais visando a ampliar a atratividade dos espaços para consumidores e trabalhadores qualificados (SCOTT, 2019). Esse tipo de intervenção ocorreu de forma irregular principalmente na cidade do Rio de Janeiro, em particular no contexto de preparação para os Jogos Olímpicos de 2016. O atual contexto de crise político-econômica coincide com o estancamento de investimentos públicos e privados após a realização dos Jogos Olímpicos de 2016, a queda da arrecadação devido à recessão e à crise motivada pela excessiva dependência criada em relação à indústria do petróleo. No contexto pós-olímpico, é visível também a crise do setor imobiliário, com grande sobreoferta de imóveis residenciais e comerciais, bem como no setor hoteleiro. Áreas revitalizadas como a região portuária da cidade poderiam ser locais em que as indústrias da cultura e do entretenimento fossem mais exploradas. Para tanto, a eliminação dos obstáculos ao empreendedorismo - em especial da burocracia, da morosidade na concessão de alvarás e da simplificação das condições para regularização de atividades econômicas criativas - seria fundamental (RAPS, 2016). Em um contexto mais amplo, a tendência ao "empreendedorismo urbano"veio se consolidando como o modelo hegemônico de planejamento da escala local no contexto de um "localismo hipercompetitivo" em relação a práticas mais autônomas de desenvolvimento local e de aprofundamento da democracia participativa no planejamento urbano (MAGALHÃES, 2008). Mesmo 
com a eliminação de obstáculos, alguns tipos de empreendedorismo urbano conduzem à formação de "cidades para o espetáculo" que mais servem aos interesses do capital do que a sua própria população, além de motivarem a gentrificação e fortalecerem processos de segregação socioambiental.

\section{Considerações finais}

Se por um lado as cidades-região vieram gradualmente tomando forma e se colocando como unidades de análise urbano-regional, elas também se colocam como locais de tensões, contradições e conflitos em torno da definição do espaço urbano. Nesse sentido, uma atuação crescente de instituições regionais e locais faz-se necessária como precondição fundamental para o desenvolvimento dessas novas unidades (BRENNER, 1998). Entretanto, tentativas de concentração da autoridade política em uma cidade-região poderiam introduzir ineficiências em assuntos administrativos, dados os diferentes níveis de escala em que os múltiplos serviços urbanos e os bens públicos são capazes de alcançar um nível ótimo de alocação, sem desconsiderar a resistência considerável daqueles que demonstram interesse em arranjos mais desagregados. Uma melhor saída seria uma estrutura de conglomerados formada por relações hierárquicas frouxas e complementada por organizações que ampliassem a efetividade operacional e incluíssem instituições não lucrativas que atendessem às necessidades sociais (SCOTT, 2019).

Entretanto, antes de se pensar em meios de governança de uma cidade-região no Estado do Rio de Janeiro, seria preciso formular uma política integrada, que aliviasse as pressões sobre a região metropolitana e permitisse explorar as potencialidades regionais. Com mais integração, a rede de cidades fluminenses poderia contribuir inicialmente para a superação da crise econômica, política e social do estado, assim como desenvolver o seu interior por meio de uma maior diversificação produtiva e uma melhor distribuição da população (LOUREIRO, 2006).

\section{Referências}

ABREU, M. A. A evolução urbana do Rio de Janeiro. 3. ed. Rio de Janeiro: IPLANRIO/ZAHAR, 1987.

ARRAIS, T. A. A cidade e a região/a cidade-região: reconhecer processos, construir políticas. Cadernos Metrópole, n. 20, p. 81-91, 2008.

BATISTA, E. L.; ALMEIDA, C. Investimento para pesquisa é insuficiente, diz cientista. Folha de S. Paulo, 2018. Disponível em: https://www1.folha.uol.com. $\mathrm{br} / \mathrm{seminariosfolha/2018/03/investimento-para-pesquisa-e-insuficiente-diz-}$ cientista.shtml. Acesso em: 4 jun. 2018.

BEZERRA, J. A. A cidade-região sob as coexistências do território. Boletim Goiano de Geografia, v. 37, n. 2, p. 158-174, 2017. 
BRENNER, N. Metropolitan institutional reform and the rescaling of state space in contemporary Western Europe. European Urban and Regional Studies, n. 10, p. 297-324, 2003.

CALDEIRA, T. Enclaves fortificados: a nova segregação urbana. Novos Estudos Cebrap, n. 47, p. 155-76, 1997.

CYSNE, R. P. Rio de Janeiro e intermediação financeira. Rio de Janeiro: EPGE/ FGV, 1996.

DAIN, S. Crise econômica: Rio de todas as crises. Rio de Janeiro: IUPERJ, 1990.

DAVIDOVICH, F. O entorno da região metropolitana do Rio de Janeiro, hipóteses e considerações. In: ENCONTRO DA ASSOCIAÇÃO NACIONAL DE PÓS-GRADUAÇÃO E PESQUISA EM PLANEJAMENTO URBANO E REGIONAL, Salvador. Anais... Salvador: ANPUR, 2001. p. 326-335.

DUARTE, H. S. B. Estrutura urbana do estado do Rio de Janeiro: uma análise no tempo. Revista Brasileira de Geografia, v. 43, n. 4, p. 477-560, 1981.

FRIEDMANN, J.; WOLFF, G. World city formation: An agenda for research and action. International Journal of Urban and Regional Research, n. 6, p. 309344, 1982.

G1 RIO. RJ teve recorde de roubo de veículos em março, registra ISP. G1 website, 17 abr. 2018. Disponível em: https://g1.globo.com/rj/rio-de-janeiro/noticia/rjteve-recorde-de-roubo-de-veiculos-em-marco-registra-isp.ghtml. Acesso em: 17 abr. 2018 .

GEDDES, P. Cities in Evolution: An Introduction to the Town Planning Movement and the Study of Civics. Londres: Williams and Norgate, 1915.HALL, P.; PAIN, K. The Polycentric Metropolis: Learning from Mega-City Regions in Europe. Londres: Routledge, 2012.

INSTITUTO BRASILEIRO DE GEOGRAFIA E ESTATÍSTICA (IBGE). Censo Demográfico. 2010. Disponível em: http://cidades.ibge.gov.br/xtras/perfil. php?lang=\&codmun=330455\&search=rio-de-janeiro|rio-de-janeiro. Acesso em: 26 maio 2019.

INSTITUTO BRASILEIRO DE GEOGRAFIA E ESTATÍSTICA (IBGE). Mais da metade da população vive em 294 arranjos formados por contiguidade urbana e por deslocamentos para trabalho e estudo. Agência IBGE Notícias, 25 mar. 2015. Disponível em: https://agenciadenoticias.ibge.gov.br/agenciasala-de-imprensa/2013-agencia-de-noticias/releases/9710-mais-da-metade-dapopulacao-vive-em-294-arranjos-formados-por-contiguidade-urbana-e-pordeslocamentos-para-trabalho-e-estudo. Acesso em: 27 mar. 2019.

INSTITUTO BRASILEIRO DE GEOGRAFIA E ESTATÍSTICA (IBGE). Arranjos populacionais e concentrações urbanas no Brasil. 2. ed. Rio de Janeiro: IBGE, 2016.

JESUS, D. S. V. A arte do encontro: a paradiplomacia e a internacionalização das cidades criativas. Revista de Sociologia e Política, v. 25, n. 61, p. 51-76, 2017a.

JESUS, D. S. V. Saudade de mim: patrimônio cultural e economia criativa no Rio de Janeiro. In: FIGUEIREDO, J. L.; JESUS, D. S. V. (Org.). Cidades criativas: aspectos setoriais e territoriais. 1. ed. Rio de Janeiro: E-papers, 2017b.v. 1. p.157-177. 
KLINK, J. J. A cidade-região: regionalismo e reestruturação na grande ABC paulista. Rio de Janeiro: DP\&A, 2001.

KNOW, P. L.; TAYLOR, P. J. World Cities in a World System. Cambridge: Cambridge University Press, 1995.

LAGO, L. C. O que há de novo na clássica dualidade núcleo-periferia: a metrópole do Rio de Janeiro. In: RIBEIRO, L. C. Q. (Org.). O futuro das metrópoles: desigualdades e governabilidade. Rio de Janeiro: Fase, 2000. p. 207-228.

LAQUIAN, A. A. Beyond Metropolis: The Planning and Governance of Asia's Mega-Urban Regions. Baltimore, MD: Johns Hopkins University Press, 2005.

LENCIONI, S. Cisão territorial da indústria e integração regional no estado de São Paulo. In: BRANDÃO, C.; GALVÃO, A. C.; GONÇALVES, M. F. (Org.). Regiões e cidades, cidades nas regiões: o desafio urbano-regional. São Paulo: Ed. Unesp, 2000. p. 465-475.

LESSA, C. O Rio de todos os brasis: uma reflexão em busca de auto-estima. Rio de Janeiro: Record, 2000.

LEWER, L. Ganhadores de Nobel pedem que Temer interrompa cortes na ciência. Folha de S. Paulo, 2017. Disponível em: http://www1.folha.uol.com.br/ ciencia/2017/09/1923338-ganhadores-de-nobel-pedem-que-temer-interrompacortes-na-ciencia.shtml. Acesso em: 4 jun. 2018.

OUREIRO, A. C. N. S. Rio de Janeiro: uma análise da perda recente de centralidade. 2006. 117 f. Dissertação (Mestrado em Economia) - Centro de Desenvolvimento e Planejamento Regional. Faculdade de Ciências Econômicas, Universidade Federal de Minas Gerais, Belo Horizonte, 2006.

MAGALHÃES, F. N. C. Da Metrópole à Cidade-Região. Na direção de um novo arranjo espacial metropolitano ? Revista Brasileira de Estudos Urbanos e Regionais, v. 10, n. 2, p. 9-27, 2008.

MARTÍN, M. Queda de braço entre Crivella e escolas de samba ameaça o Carnaval 2018 no Rio. El País, 16 jun. 2017. Disponível em: https://brasil. elpais.com/brasil/2017/06/15/cultura/1497557739_810021.html. Acesso em: 24 set. 2017.

MOREIRA, I. C. Um momento de crise e de desafios para a ciência brasileira. $\mathbf{O}$ Globo, 2018. Disponível em: https://blogs.oglobo.globo.com/ciencia-matematica/ post/um-momento-de-crise-e-de-desafios-para-ciencia-brasileira.html. Acesso em: 4 jun. 2018.

NATAL, J. O Estado do Rio de Janeiro pós-1995: dinâmica econômica, rede urbana e questão social. Rio de Janeiro: Pubblicati/FAPERJ, 2005.

O ESTADO DE S. PAULO. Em decadência política, Rio viverá uma década de crise.Estadão, 23 abr. 2017. Disponível em: http://politica.estadao.com.br/noticias/ geral,em-decadencia-politica-rio-vivera-uma-decada-de-crise,70001748272. Acesso em: 24 set. 2017.

OLIVEIRA, L. A. G. Cultura, criatividade e desenvolvimento territorial: reflexões sobre Redes e Sistemas Produtivos de Economia Criativa. In: LEITÃO, C.; MACHADO, A. F. (Org.). Por um Brasil Criativo: significados, desafios e perspectivas da economia criativa brasileira. Belo Horizonte: Código Editora, 2016. p. 109-125. 
PARR, J. B. Perspectives on the city-region. Regional Studies, v. 39, n. 5, p. 555$566,2005$.

PREFEITURA DO RIO DE JANEIRO. Prefeitura.rio, 2017. Disponível em: http://www.rio.rj.gov.br/web/guest/conteudos?categoria=\&tag=\&estrutura $=\mathrm{S}$ TR-NOTICIA. Acesso em: 22 out. 2017.

PRETECEILLE, E.; VALLADARES, L. Favela, favelas: unidade ou diversidade da favela carioca. In: RIBEIRO, L. C. Q. (Org.). O Futuro das metrópoles: desigualdades e governabilidade. Rio de Janeiro: Revan: FASE, 2000 p. 375-403.

RANDOLPH, R. Utopia burguesa ou revolução urbana? - Transformações da organização territorial e novas formas urbanas em áreas peri-metropolitanas do Rio de Janeiro. In: ENCONTRO NACIONAL DA ANPUR, 11., 2005, Salvador. Anais... Salvador: Anpur, 2005. p. 538-554.

RAPS. Plataforma de Sustentabilidade para o Rio de Janeiro. RAPS website, 2016. Disponível em: https://www.raps.org.br/site/wp-content/ uploads/2016/07/2016-7-18_Plataforma-de-Sustentabilidade-Rio-de-Janeiro. pdf. Acesso em: 14 dez. 2016.

ROSSI, A. Congresso aprova decreto de intervenção federal no Rio de Janeiro; entenda o que a medida significa. BBC Brasil, 21 fev. 2018. Disponível em: http:// www.bbc.com/portuguese/brasil-43079114. Acesso em: 15 abr. 2018.

RUIZ, R. M. As estruturas urbano-regionais do Brasil e Estados Unidos comparadas: um estudo exploratório. In: SEMINÁRIO SOBRE A ECONOMIA MINEIRA, ?, 2004. Diamantina. Anais... Diamantina: UFMG/CEDEPLAR, 2004. p. 1-21.

SASSEN, S. The Global City: New York, London, Tokyo. Princeton, NJ: Princeton University Press, 1991.

SCHWARTZMAN, S. (Coord.). Ciência e tecnologia no Brasil: uma nova política para um mundo global. São Paulo: FGV, 1993.

SCOTT, A. J. City-regions reconsidered. EPA: Economy and Space, v. 0, n. 0, p. 1-27,2019. Disponível em: https://www.researchgate.net/publication/331203195_ City-regions_reconsidered. Acesso em: 15 abr. 2018.

SOJA, E. Postmetropolis: Critical studies of cities and regions. Oxford: Blackwell, 2000.

SORKIN, M. Variations on a Theme Park: The New American City and the End of Public Space. Nova York: Hill and Wang, 1992.

STORPER, M. The Regional World: Territorial Development in a Global Economy. Nova York, Londres: Guilford Press, 1997.

WALDINGER, R. The immigrant niche in global city-regions: Concept, patterns, controversy. In: SCOTT, A. J. (Ed.). Global City Regions: Trends, Theory, Policy. Oxford: Oxford University Press, 2001. p. 299-322.

WERMUTH, M. A. D. Medo, direito penal e controle social. Revista da Faculdade de Direito, v. 39, n. 1, p. 133-168, 2011.

Submetido: $31 / 03 / 2019$.

Aceito: 27/05/2019. 


\title{
NEAR CITY, DISTANT REGION: OBSTACLES TO A CITY-REGION INTHE STATE OF RIO DE JANEIRO
}

\begin{abstract}
The purpose is to examine the obstacles for the population arrangement Rio de Janeiro/RJ to articulate with other arrangements in the state and form a polycentric and multifunctional agglomeration in the form of a city-region. Based on the theoretical work of Allen Scott and a qualitative methodology focused on document and bibliographic research, the central argument of this theoretical essay which uses the state of Rio de Janeiro as a case study points out that such obstacles are related to the fact that the state of Rio de Janeiro developed a weak urban network due to the existence of few intermediate centers, in particular outside the metropolitan limits, due to the deficiencies of productive infrastructure. These centers were not defined as alternatives to the industrial location or specialized interconnected services. More recently, critical articulations of production, trade, and financial relations have been weakened by the worsening of urban violence, the state's economic and fiscal crisis, and allegations of corruption by state authorities, as well as the lack of stimulus to the diversity of cultural production and the limitation of resources for innovation. Previously existing problems hinder the integration necessary for the constitution of a city-region, such as the political-social deficit of each arrangement when managing issues generated or fed by integration.
\end{abstract}

Keywords: City-region. Rio de Janeiro. Cognitive capitalism. Urban planning. Regional planning.

\section{CIUDAD PRÓXIMA, REGIÓN DISTANTE: LOS OBSTÁCULOS A UNA CIUDAD-REGIÓN EN RÍO DE JANEIRO}

\begin{abstract}
Resumen
El objetivo es examinar los obstáculos para el arreglo poblacional Río de Janeiro / RJ articularse con otros arreglos en el propio Estado y configurar una aglomeración policéntrica y multifuncional de una ciudad-región. Con la referencia teórica de la obra de Allen Scott y una metodología cualitativa embasada en pesquisas documental y bibliografica, el argumento central de este ensayo teórico que utiliza el estado de Rio de Janeiro como estudio de caso apunta que tales obstáculos están relacionados al hecho de que el Estado de Río de Janeiro desarrolló una débil red urbana debido a la existencia de pocos centros intermediarios, en particular fuera de los límites metropolitanos, frente a las deficiencias de infraestructura productiva. Estos centros no se definieron como alternativas para la localización industrial o servicios especializados interconectados. Recientemente, las articulaciones críticas de la producción, comercio y relaciones financieras se debilitaron con el agravamiento de la violencia urbana, la crisis económica y fiscal del Estado y las denuncias de corrupción por las autoridades estatales, así como la falta de estímulos a la diversidad de la producción cultural y la limitación de recursos para la innovación. Problemas previamente existentes dificultan la integración necesaria a la constitución de una ciudad-región, como el déficit político-social de cada arreglo al administrar cuestiones generadas o alimentadas por la integración.
\end{abstract}

Palabras clave: Ciudad-región. Rio de Janeiro. Capitalismo cognitivo. Planificación urbana. Planificación regional. 